
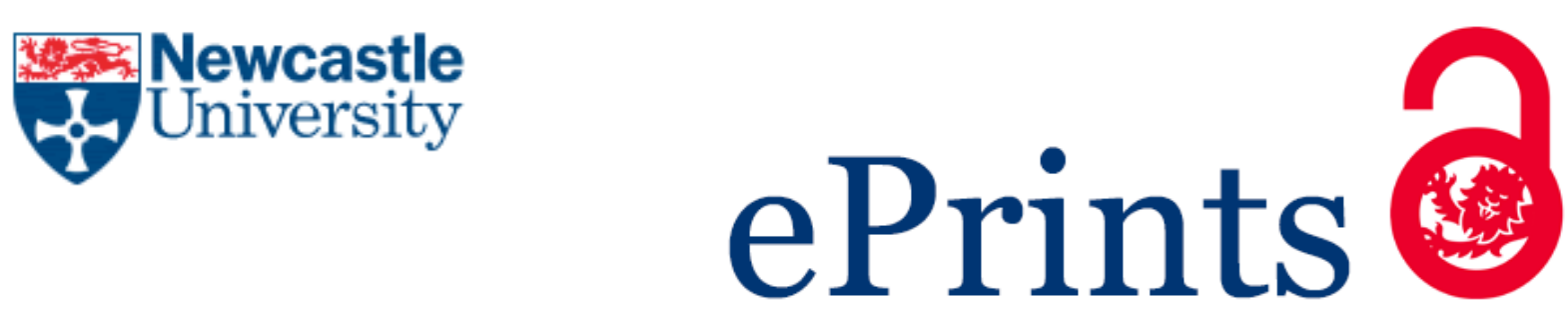

Ferrari C, Puliafito PP, Tei A.

Dynamics in terminal concessions: the role of performances.

Maritime Economics \& Logistics 2017

DOI: http://doi.org/10.1057\%2Fs41278-017-0073-9

\title{
Copyright:
}

The final publication is available at Springer via http://doi.org/10.1057\%2Fs41278-017-0073-9

DOI link to article:

http://doi.org/10.1057\%2Fs41278-017-0073-9

Date deposited:

$24 / 05 / 2017$

Embargo release date:

03 May 2018 


\section{Dynamics in terminal concessions: the role of performances}

Claudio Ferrari- Department of Economics, School of Social Sciences, University of Genova, Italy

Pier Paolo Puliafito - Department of Informatics, Bioengineering, Robotics and Systems Engineering, University of Genova, Genova, Italy

Alessio Tei - School of Marine Science and Technology, Newcastle University, Newcastle upon Tyne, United Kingdom

\section{Abstract}

A terminal concession agreement represents the final outcome of a negotiation (that may take different legal forms) among a port authority and one or more terminal operators. In most cases it defines the duties and responsibilities of the two parties for a very long period of time. Once the concession is awarded, its legal obligations remain (or ought to remain) fixed irrespective of changes that may happen in the port industry. In this sense, authors have often raised the question whether modifications to the current concession fee structure are possible in order to align public and private goals, and increase terminal performance. The importance of this issue lies in the fact that, in several port governance models, concessions are static agreements in which fees and other conditions in general do not change over time. The current paper addresses this issue, discussing the possibility - and the advantages - of introducing a dynamic approach, able to guarantee benefits to both the terminal operator and the Port Authority. To achieve this goal, the paper develops a methodology based on dynamic incentives, based on the relative performance of a port terminal operator in respect of its competitors.

Keywords: Concession fee, Port competitiveness, Port concession, Concession management, Variable fee, Terminal performance 


\section{Introduction}

In the last years, an increasing number of reports (e.g. ITMMA, 2008; Verhaegen, 2011) and academic papers (e.g. De Filippi, 2004; Ferrari and Basta, 2009; Notteboom and Theys, 2010; Ferrari et al., 2013; Wang and Pallis, 2014) have pointed out the strategic role of terminal concession agreements, within the management of any port activity, and how concession agreements might influence both port competitiveness and investments. That research mainly concerned seaports structured on landlord models in which a Port Authority (PA) has the main duty to plan port development (Goss, 1990; Meersman et al., 2009) but in which terminal activities are performed by private companies (Suykens and Van de Voorde, 1998). Terminal operators (TOC) thus acquire a "monopoly" within their own terminal area for a given number of years (usually around 20 years, although much longer periods are not uncommon). Concession agreements set all the main rules governing the relation between the PA and the TOC, thus becoming a strategic tool to assure an alignment between PA and the TOC interests, goals and responsibilities.

The involvement of private companies in port activities has been extensively studied in the past and it is a more or less common pattern, shared by all main port systems (Baird, 2000; Van Niekerk, 2005; Everett and Ross, 2007; Cullinane and Brooks, 2007). Several authors underlined how "privatization" of ports has been one of the most relevant trends in the port industry. As argued in some studies (e.g. Baird, 2000; Ferrari et al., 2013), while port privatization has generally been seen as a way to attract private capital and increase terminal efficiency (De Langen and Heij, 2014) not all ports have been able to achieve these goals (e.g. increased competitiveness due to the new governance). On the other hand, at least in EU and North America - as pointed out by Wang and Pallis (2014), Parola et al. (2012) and Notteboom et al. (2010) -, concession agreements do not normally contain specific performance clauses and only recently they have posted to be awarded through competitive tenders. Moreover, renewal procedures have also been criticized (e.g. ITTMA, 2008), being often based on supplementary agreements between Port Authority and incumbent operator, leaving no space for competitive bids from other interested terminal companies. Finally, 
since terminal operations are directly performed and controlled by the stevedore, the Port Authority is normally left with just a planning and regulatory role, with a limited possibility to influence the ongoing activity, since everything has been agreed in advance within the concession agreement.

The above scenario sets several critical issues such as the need of clear rules, balancing private and public interests, the efficiency of the awarding process in choosing the most competitive bid, a renewal process capable of assuring future performance once the concession period is ended and an incentivising concession fee evaluation method. While general approaches to all these issues are well studied in the general economic literature, in both auction theory (Krishna, 2010) and in the theory of incentives (Prendergast, 1999), port related literature has instead focused on specific elements such as: the characteristics of an efficient awarding process in the case of terminals (Notteboom and Theys, 2010 and Notteboom et al., 2010; Saeed and Larsen, 2011); the weaknesses of the current concession framework in the EU port system (Verhoeven, 2010 and 2011); efficient terminal size and other physical characteristics (Kaselimi et al., 2011; Felicio et al., 2014); port infrastructure tariffs (e.g. Bandara and Nguyen, 2016) and related PA's revenues (e.g. Chen and Liu, 214); etc.

A growing number of papers have tried to address two fundamental issues concerning the possible improvements to the concession fee calculation method (Chen and Liu, 2014; Wang and Pallis, 2014), and the concession renewal mechanism (Notteboom and Theys, 2010; Cardadeiro and da Silva, 2015). In spite of this, only few attempts have tried to discuss a dynamic approach that could link the concession fee to market developments and contract duration (Ferrari et al., 2013). For this reason, the present paper attempts to strike a balance between terminal competitiveness and throughput, which could be linked to the concession fee. To do so, a general formulation of the relationship between terminal market share and terminal traffic has been identified and tested, using data from previous studies. The two elements (i.e. port traffic and market share) even if connected are not determined by each other, since market share represents a measure of 
performance also related to the behaviour of main terminal competitors and the traffic value does not guarantee any information about the competitiveness level. Our approach will hopefully help to better understand the consequences of linking concession fees to traffic fluctuations, and to underline the advantages TOCs and PAs could obtain from a dynamic concession fee, in terms of incentives, terminal activity, and financial income. The regulatory framework of the Italian port system is used as a case in point.

The paper is organised as follows. After this brief introduction, the theoretical background is presented in section 2 , while section 3 is dedicated to the discussion of the proposed methodology. Section 4 presents an example of possible application and section 5 concludes, including ideas for further research.

\section{Theoretical Background}

The Italian port system has been recently modified by Legislative Decree 169/2016, among others reducing the number of port authorities from 24 to 15 "port system" authorities (Parola et al., 2017). The former governance model, however, i.e. that of landlord ports, remains intact: Ports retain their planning and regulatory powers, as well as the right to award concessions of terminal areas to private stevedoring companies and other port and terminal operators (Parola et al., 2012).

Despite the already planned modifications in terms of national port governance regulation that will come into effect by the end of 2016, concession policy will not change either, leaving to the concession fee a mere role of patrimonial value of the "rented" terminal areas, as the one described in (1).

$F_{i}=F_{i-1}$ ir $\Omega$

where $F_{i}$ is the fee per sqm in year $i . F$ is the patrimonial value estimated by taking into account historical construction costs (in some cases even adjusted to current values), and multiplied by an 
inflation rate, ir. $\Omega$ is a coefficient which applies if certain infrastructure characteristics are present (e.g. pavement, draft, degree of maintenance, accessibility, etc.). From the resulting value, further discounts could be applied when the TOC commits to certain investments or other special conditions. As far as increases are concerned, concession fees are rather static, changing only in accordance to expected inflation (Parola et al., 2012; Ferrari et al., 2013). We here introduce the possibility to have a dynamic approach to concession pricing, aimed at linking the concession fee to changing market conditions and to terminal performance (i.e. cargo throughput). The concession fee formula could thus become:

$F_{i}=F_{i-1}-\alpha_{i}\left(M_{i}-M_{i-1}\right)$

Here, the fee in year $i$ is determined by the annual performance of the terminal. $M$ represents the market share of the terminal, i.e. the ratio between the throughput of the analysed port and the sum of the throughput of the competing ports, the analysed port included, while $\alpha$ is a parameter to be determined. This implies the definition (agreed with the concessionaires) of the "relevant" market for a given port, defined by the set of similar ports (in terms of size, imports and exports characteristics, etc.) and/or serving a similar hinterland. Given the abovementioned hypothesis, in our case the fee is calculated at the end of the year when all the main data (i.e. throughput of the terminal and that of its competitors) are known.

The effects of positive variations in market share will generate a reduction in the terminal concession fee whereas a form of "penalty" will be applied each time the terminal registers a reduction in its market share. It is important to note, however, that variations in throughput (and their consequences) should be additionally considered in advance during the bidding procedure - as further discussed in the paper - and made clear to all contenders, to avoid future disputes or even litigation, which can be very disruptive.

Figure 1 shows four possible combinations of the two essential terminal activity variables: throughput and market share. For each possible combination of variations in $T$ (terminal 
throughput) and $M$ (market share), a different competitive position of the terminal is represented, with different possible effects on the concession fee. In fact, in the first quadrant $(\Delta M>0$ and $\Delta T>$ $0)$ the terminal is increasing its activity and its market share too; in the second quadrant $(\Delta M>0$ and $\Delta T<0)$ despite the throughput decrease the terminal is still performing better than the reference market; in the third quadrant $(\Delta M<0$ and $\Delta T<0)$ terminal activity is not only decreasing, but the terminal is also performing worse than the market; the fourth quadrant $(\Delta M<0$ and $\Delta T>0$ ) underlines a situation in which, despite throughput growth in absolute values, the terminal is not performing as well as the market. Thus, the first quadrant represents the obvious goal of both the port and the terminal operator. The second quadrant represents a good management of a market crisis by the terminal operator. The third and fourth quadrants represent a not optimal management by the terminal operator of either a "crisis" or a growing stage, respectively. Thus, incentives and penalties could be tuned with respect to both terminal activity (i.e. $\Delta T$ ) and to what terminal competitors register (i.e. $\Delta M$ ).

Figure 1 - Relationships between throughput and market share variations

II Quadrant
$\begin{aligned} & \text { Terminal throughput decreasing } \\ & \text { less than that of competitors }\end{aligned}$
$\begin{aligned} & \text { Terminal throughput decreasing } \\ & \text { more than that of competitors }\end{aligned}$
$\begin{aligned} & \text { Terminal throughput growing } \\ & \text { more than that of competitors } \\ & \text { lil Quadrant than that of competitors }\end{aligned}$
IV Quadrant


Location on different quarters would then imply potential discounts (or penalties) depending on the competitive performance of the terminal (i.e. differences in market share), and the generated terminal throughput.

Eventually, Ferrari et al. (2013) concluded their research underlining that different economic measures on the value of a concession affect both PA and TOC income, since concession fees are one of the main revenue sources for the Italian PAs, and one of the main cost items for the terminal operators, mainly in the case of container traffic. Thus, these authors discussed the possible introduction of a method that might balance the incentive (penalty) associated to the concession fee with the collected port taxes as a result of the TOC's throughput. In other words, port taxes from terminal activity could 'finance' the incentive, whereas a penalty of non-performance could top up lost port taxes (that is $k^{t} T$, where $T$ is the terminal throughput and $k^{t}$ is the port tax in euros per ton). In the end, the proposed method should represent a win-win strategy in which the TOC should enjoy decreasing concession fees, while the PA would not lose financial resources, as a result of the increasing traffic and thus port taxes too. In this situation, the "neutral effect" given by the balance of different PA's financial resources can set a lower bound whenever the discount given to concession operator does not exceed the increase in collected port taxes (and vice versa). In principle, also this lower bound could be acceptable from the PA's point of view given the long run benefits that an increased throughput could generate for the port (e.g. investment, location advantages) despite the reduced benefits in the short term.

Although Ferrari et al (2013) tested their method in the case of the port of Genoa, using historical data, they came short of generalising the discussion, so as to better identify a balance between market share and throughput performance. Clearly, however, the relation between $M$ and $T$ (or $\Delta M$ and $\Delta T$ ), is fundamental in the rationale of the proposed method, and to be able to generalise (2). 


\section{Generalisation of the background}

The relationship linking variations in market share and throughput can be expressed as in equation (3):

$\Delta M_{i, i-1}^{u, *}=M_{i}^{u, *}-M_{i-1}^{u, *}=\frac{T_{i-1}^{u, *}+\Delta T_{i, i-1}^{u, *}}{\sum_{j \neq u} T_{i}^{j, *}+T_{i-1}^{u, *}+\Delta T_{i, i-1}^{u, *}}-M_{i-1}^{u, *}$

In which $M$ represents the market share in year $i$ of port $u$, belonging to a set of ports that defines the relative competitors' market, given by ports $j$, i.e. the other ports of the market. Values identified with $*$ represent those results that were already registered at the time of the fee evaluation. Equation (3) represents an elaboration of market share differences and their relation with performances, as represented by throughput, and with the relative performance of competing ports.

Considering the issue of the financial neutrality for the PA, it is worth noting that for every couple of measured values $\left(\Delta T^{*}, \Delta M^{*}\right)$ included in the eq. (3) there will be a $k^{m}$ that meets the following relation:

$k^{t} \Delta T_{i, i-1}^{* u}+k^{m} \Delta M_{i, i-1}^{* u}=0$

$k^{m}=-\frac{k^{t} \Delta T_{i, i-1}^{* u}}{\Delta M_{i, i-1}^{* u}}$

where $k^{m}$ is a kind of conversion factor which assigns a monetary value to a market share. Therefore Equation (4) represents the discount (penalty) for the TOC, as well as the concept of financial neutrality for the PA, ensuring that for each positive (negative) change in throughput (i.e. port taxes) there is a bonus (malus) in the concession fee. Thus, equation (4 a) represents that value able to guarantee that each variation in the collected port taxes is compensated by an equal variation in the fee. 
The balance is ensured by equation (2), using a compensation factor defined as $\propto_{i}=k^{m}$ applied to a single year. Moreover, the equation (4) can be used to evaluate different effects in terms of both revenues and competitiveness trends. Once the "neutrality condition" is set, incentives could be tuned according to the different combinations of $\Delta M$ and $\Delta T$. For instance, in the case of quadrant 1 of figure 1 , relatively high discounts to the terminal operator might be guaranteed, while different values of incentives or penalties should be considered for the other three quadrants.

The "full" compensation strategy seems to be very precise but at the same time it could be excessively rewarding or punitive, especially if applied for short periods, such as an annual fee review. But very important counterintuitive conclusions may also occur using jointly (2) and (4), for example in the quadrant 4. Hence, it is important to generalise the relation among variables, in order to increase understanding on the consequences of applying such method based on throughput and market share.

Since normally variations are measured as percentages (as in figure 1), the percentage variation of market share relation can be introduced, based on historical values:

$$
\begin{aligned}
& P C M_{i, i-1}^{u, *}=\frac{M_{i}^{u, *}-M_{i-1}^{u, *}}{M_{i-1}^{u, *}}=\frac{1}{M_{i-1}^{u, *}}\left(\frac{T_{i-1}^{u, *}}{T_{i-1}^{u, *}} \frac{T_{i-1}^{u, *}+\Delta T_{i, i-1}^{u, *}}{\sum_{j \neq u} T_{i}^{j, *}+T_{i-1}^{u, *}+\Delta T_{i, i-1}^{u, *}}-M_{i-1}^{u, *}\right)= \\
= & \frac{1}{M_{i-1}^{u, *}} \frac{1+\frac{\Delta T_{i, i-1}^{u, *}}{T_{i-1}^{u, *}}}{\frac{\sum_{j \neq u} T_{i}^{j, *}}{T_{i-1}^{u, *}}+1+\frac{\Delta T_{i, i-1}^{u, *}}{T_{i-1}^{u, *}}}-1=\frac{1}{M_{i-1}^{u, *}} \frac{1+P C T_{i, i-1}^{u, *}}{\frac{\sum_{j \neq u} T_{i}^{j, *}}{T_{i-1}^{u, *}}+1+P C T_{i, i-1}^{u, *}}-1
\end{aligned}
$$

where $P C$ represents the percentage variation of a given quantity $(M$ or $T)$. (5) is simply a quantitative balance that becomes an equation if the percentages assume the role of variables. It is then possible to analyse the interdependent behaviour of the variation of throughput and of market share in the given period of time. To simplify the notations, we pose: 
$P C M_{i, i-1}^{u}=\frac{M_{i}^{u}-M_{i-1}^{u, *}}{M_{i-1}^{u, *}}=y \quad P C T_{i, i-1}^{u}=\frac{T_{i}^{u}-T_{i-1}^{u, *}}{T_{i-1}^{u, *}}=x$

$T_{i-1}^{u, *}=a^{*} \quad \sum_{j \neq u} T_{i}^{j, *}=c^{*} \quad M_{i-1}^{u, *}=b^{*}$

Obtaining:

$y=\frac{1}{b^{*}} \frac{a^{*}(1+x)}{c^{*}+a^{*}(1+x)}-1$

where $x$ and $y$ are now the studied variables (i.e., percentage variation of throughput and market share, respectively).

Equation ( 5 a) is defined only if $x \geq-1$. Moreover, when $x=-1$, then $y=-1$.

The intersection with the axis will happen in:

$\begin{array}{ll}P C T_{i, i-1}^{u}=x=0 & y=P C M_{i, i-1}^{u}=\frac{1}{b^{*}} \frac{a^{*}}{c^{*}+a^{*}}-1 \\ P C M_{i, i-1}^{u}=y=0 & x=P C T_{i, i-1}^{u}=\frac{b^{*} c^{*}}{a^{*}\left(1-b^{*}\right)}-1\end{array}$

\section{Application}

Given the set of parameters $a, b$ and $c$, it is possible to plot the function $(x, y)$ in order to understand how market share might vary depending on terminal throughput. Also an alternative exogenous input (parameter $c$ ) might be considered aiming at the assessment of the effect of a change in the market on the reported terminal market share. We here assume that a change in the market takes place each time the traffic of competing ports changes, directly affecting - ceteris paribus - the market share of the studied terminal. Both exercises contribute to better compare and understand the effect of changes in the terminal performance and in the performance of its competitors on port competitiveness. 
Figure 2 presents different curves, derived from a function $(x, y)$, for a given set of $a$ and $b$. More precisely, any curve represents the set of possible combinations of $x$ and $y$, given $c$, which is a shift factor, producing the different curves.

To achieve the above mentioned goal of assessment, here based on a binomial performance composed by throughput and market share, different assumptions can be made. Given $x^{*}, a^{*}, b^{*}$, and $c^{*}$, the value of $y^{*}$ can be determined. Subsequently, we vary either $x$ or $c$, to better understand the impact of terminal throughput, or of the traffic of competitors on $y$, underlining where the terminal is located in the different quadrants of Figure 1.

A real case scenario is introduced as an example. This concerns an Italian container terminal, in a relatively small market. In year $i-1$ the terminal handled 35,000 tons (i.e. $a^{*}$ ), having a market share (i.e. $b^{*}$ ) equal to $18 \%$. In the reported year $i$, competitors handled 200,000 tons (i.e. $c^{*}$ ) while the reported $x^{*}$ was equal to $8.5 \%$. Accordingly the value of $y^{*}$ is equal to $-11 \%$. In this scenario - i.e. growth in $T$ but decrease in $M$ - the terminal is located in the fourth quadrant. Let us then try to understand how different values of $x$ (or $c$ ) would affect $y$ and the meaning of these hypothetical variations.

Figure 2 Family of curves depending on $c$ 


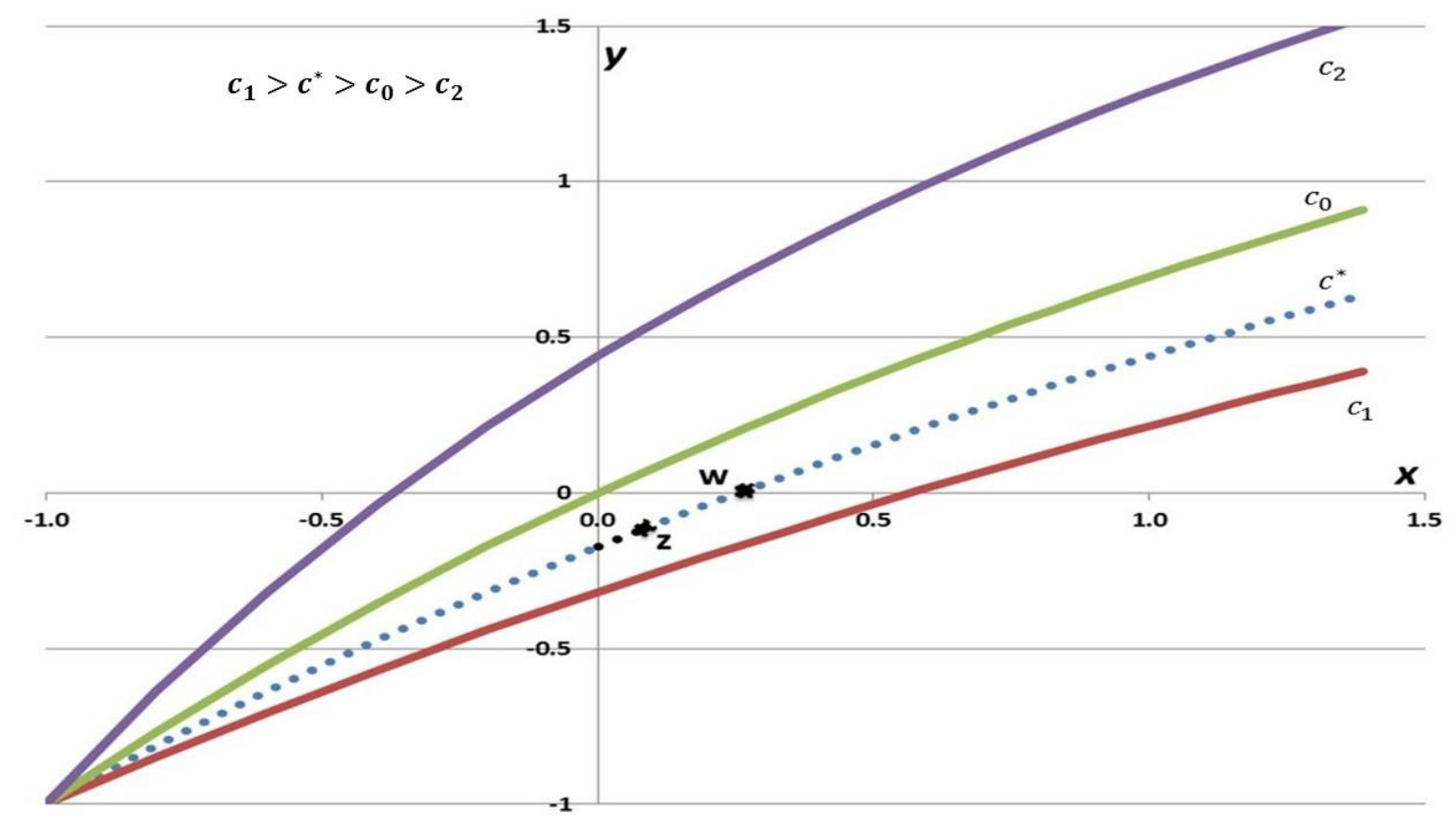

Figure 2 shows different combinations of $(x, y)$, along each line, and the different lines produced by variations in $c$ (i.e. $c_{1}>c^{*}>c_{0}>c_{2}$ ). The dotted curve $\left(c^{*}\right)$ represents the variation of $x$ given the data shown earlier in the example, where the $z$ represents the calculated value of the example (i.e. $\left.x^{*}, y^{*}\right)$. The curve related to $c_{0}$ represents the situation in which the competitor ports' performance would have enabled the terminal operator to perform exactly as in the previous period (i.e. passing through the origin point), without any change in throughput. Other two represented curves in the figure are situations in which the terminal has performed less (i.e. $c_{1}$ ) and more (i.e. $c_{2}$ ) than the competitors.

Fig. 2 shows how, depending on the annual performance, our terminal (i.e. $x^{*}$ ) may lie in three different quadrants, depending on the movements on the dotted curve. For instance, if the terminal performs better, it has the chance to reach the first quadrant. In this regard, it is important to note that each curve represents a family of possible corrections from the situation $\left[x^{*}, y^{*}\right]$ in which:

$T_{i}^{u}=a^{*}(1+x)$

$$
M_{i}^{u}=\frac{a^{*}(1+x)}{c^{*}+a^{*}(1+x)}
$$


Thus, once a certain combination $[x, y]$ is registered, it is possible to evaluate different alternative situations.

Once the related curve is drawn - as expressed in equations (6) and (7) -, its intersections with the axes represents the variation in $\Delta T(\Delta M)$, had $M(T)$ remained unchanged in respect to the previous reported period. For example, point $w$ represents how $T$ (throughput) should have grown to ensure the same market share as in previous year.

Studying the first derivative of any curve in the Fig. 2 it is possible to determine parts of the curve in which a value of the derivative greater than 1 means that a variation in throughput determine a greater increase in market share. On the other hand, derivative values below 1 mean that, to increase $M$, the terminal must register a major increase in $T$. The position of the terminal above or below this threshold is not exclusively dependent on its activity, but also on the value of $c$, that is the throughput registered by its competitors. It is important to note - as it can also be noticed from Fig. 2 - that in the third quadrant it is easier to register higher values of derivatives than in the first quadrant.

Finally, interesting information can be obtained by looking at how $c$ shifts the curve. Comparing the distances among the curves, it is possible to understand the different impacts of market conditions on our terminal's competitive position. In other words, for a certain throughput variation $x$, the competitive position of our terminal would have changed if the market had developed differently. In this regard, the distance among the curves could be used as proxy for the sensitivity of our approach (and then the modification of the parameters) to changing market conditions. 


\section{Effects on port actors}

In general terms, the introduction of variable concession fees, apart from its effects on a terminal's competitive position, could also be used as leverage, leading to the optimization of port facilities, by affording different incentives to all actors involved.

Firstly, the Port Authority may consider financial neutrality as a lower bound with regard to differences between concession fee and port taxes, as expressed in (4), while it pushes the TOC to maximize its competitive position, in line with the PA's goals. On the other hand, in spite of the TOC's financial uncertainty due to the variable concession fee, the TOC would at the same time decrease its costs thanks to the related discounts. Moreover, as demonstrated in the analysis of eq. (5), the study of market conditions could lead PA and TOC to agree on a mix of approaches that could balance the outcomes for both actors. At the same time, both actors would be jointly aware of the impact of changing market conditions on the concession fee variability. Thus, from a port and local community point of view, such a method could ensure both the optimization of port infrastructure and a relative control on port activities managed by the private operators.

\section{Concluding remarks}

This paper discussed a new, dynamic and variable concession fee methodology, introducing a system of incentives (penalties) depending on terminal performances. Our analysis of the relationship between market share and terminal throughput allowed us to identify ways of introducing a system of incentives (penalties) to the concession fee that could be potentially attractive to both PA and TOC. As shown, different values, even in the same quadrant (Fig. 1), would lead the PA to different conclusions, and subsequent incentives (or penalties). First, the relative position of TOC performance means that, for the PA, it makes a difference if the operator is managing the terminal well, vis à vis its competitors. In such a case, the PA could align the concession fee to the trend of the TOC's activity against the market. Third, our approach could be easily developed as tool to understand how 
the terminal should have performed to achieve at least the same competitive position of the previous year.

Although our analysis was limited in the specification of (1), our methodology could be generalised as in eq. (8) below.

$F_{i}=f\left(P C M_{i, i-1}^{u, *}, P C T_{i, i-1}^{u, *}\right)$

Equation (8) is of course a non-linear generic expression of relations (1), while (2) is a very particular case of (8). Moreover, this function, valid for only one year, could be adapted to make a multi-period analysis, allowing PAs to design better incentives according to different scenarios. Thus, the study of various specifications of (8) can allow local authorities to achieve specific goals, using versions of the function that more closely represent their objectives, as well as the starting conditions of terminal operators.

Despite the limitations related to the impossibility of recreating real market conditions, further research could focus also on the relationship between competitors' throughput and terminal throughput, in order to better investigate how exogenous variations could be considered in the design of incentives or penalties to be included in the annual reviews of concession fees.

\section{Acknowledgements}

The authors are grateful to the two anonymous referees and to the Editor-in-chief for their valuable revisions and suggestions. We believe they deeply contributed to improve our work. Any further error remains solely authors' responsibility. 


\section{References}

Baird, A. (2000) Port privatisation: objectives, extent, process, and the UK experience. International Journal of Maritime Economics 2(3): 177-194.

Bandara, Y.M. and Nguyen, H.O. (2016) Influential factors in port infrastructure tariff formulation, implementation and revision. Transportation Research Part A 85: 220-232.

Cardadeiro, E. and da Silva, J.A. (2015) Another model for Terminal Concessions' Selection Criteria. Proceedings of the SIGA2 Conference; Antwerp, $11^{\text {th }}-13^{\text {th }}$ May 2015, Antwerp.

Chen, H.C. and Liu, S.M. (2014) Optimal concession contracts for landlord port authorities to maximise fee revenues. International Journal of Shipping and Transport Logistics 6(1): 26-45.

Cullinane, K. and Brooks, M.R. (2007) Devolution, Port Governance and Port Performance. Oxford: Elsevier.

de Langen, P. and Heij C. (2014) Corporatisation and performance: a literature review and an analysis of the performance effects of the corporatisation of port of Rotterdam authority. Transport Reviews, 34: 396-414.

Defilippi, E. (2004) Intra-Port Competition, Regulatory Challenges and the Concession of Callao Port. Maritime Economics \& Logistics 6(4): 279-311.

Everett, S. and Robinson, R. (2007) Port Reform: The Australian Experience. Research in Transportation Economics, 17: 259-284.

Felicio, J.A., Caldeirinha, V. and Dionisio, A. (2015) The effect of port and container terminal characteristics on terminal performance. Maritime Economics \& Logistics 17(4): 493-514.

Ferrari, C. and Basta, M. (2009) Port concession fees based on the price-cap regulation: A DEA approach. Maritime Economics \& Logistics 11(1): 121-135. 
Ferrari, C., Puliafito, P.P. and Tei, A. (2013) Performance and quality indexes in the evaluation of the terminal activity: a dynamic approach. Research in Transportation Business and Management 8: 7786.

Galvao, C.B., Robles, L.T. and Guerise, L.C. (2013) The Brazilian seaport system: A post-1990 institutional and economic review. Research in Transportation Business and Management, 8: 17-29.

Goss, R.O. (1990) Economic policies and seaports: 1. The economic functions of seaports. Maritime Policy and Management 17(3): 207-219.

Informare (2016). www.informare.it

ITTMA - Institute Of Transport and Maritime Management Antwerp (2008) The Awarding of Seaport Terminals in Europe: Results from ITMMA Survey Commissioned by ESPO, Antwerp.

Kaselimi, E., Notteboom, T. and De Borger, B. (2011) A game theoretical approach to competition between multi-user terminals: the impact of dedicated terminals. Maritime Policy and Management 38(4): 395-414.

Krishna, V. (2010) Auction Theory. New York: Elsevier.

Meersman, H., Van de Voorde, E. and Vanelslander, T. (2009) Future Challenges for Port and Shipping Sector. London: Informa.

Notteboom, T. (2007) Concession agreements as port governance tool. Research in Transport Economics 17: 437-455.

Pallis, A., Notteboom, T. and de Langen, P. (2008) Concession agreements, capabilities and market entry. Maritime Economics and Logistics, 10(3): 209-228.

Parola, F., Ferrari, C., Tei, A. Satta, G. and Musso, E. (2017) Dealing with multi-scalar embeddedness and institutional divergence: Evidence from the renovation of Italian port governance. Research in Transportation Business and Management 22: 89-99. 
Parola, F., Tei, A. and Ferrari, C. (2012) Managing port concessions: evidence from Italy. Maritime Policy and Management, 39(1): 45-61.

Prendergast, C. (1999) The provision of incentives in firms. Journal of Economics Literature 37(1): 763.

Saeed, N. and Larsen, O.I. (2010) Container terminal concessions: A game theory application to the case of the ports of Pakistan. Maritime Economics \& Logistics 12(3): 237-272.

Suykens, F. and Van de Voorde, E. (1998) A quarter a century of port management in Europe: objectives and tools. Maritime Policy and Management, 25(3): 251-261.

Theys, C. and Notteboom, T. (2010) Determining terminal concession durations in seaports. Journal of International Logistics and Trade, 8(1): 13-40.

Theys, C., Notteboom, T., Pallis, A. and de Langen, P. (2010) The economics behind the awarding of terminals in seaports. Research in Transport Economics, 27(1): 37-50.

Van Niekerk, H.C. (2005) Port Reform and Concessioning in Developing Countries. Maritime Economics \& Logistics 7(2): 141-155.

Verhoeven, P. (2010) A review of port authority functions: Towards a renaissance?. Maritime Policy and Management 37(3): 247-270.

Verhoeven, P. (2011) European Port Governance. Report of an Enquiry into the Current Governance of European Seaports, The ESPO Fact Finding Report, Limassol.

Wang, G. and Pallis, A. (2014) Incentive Approaches to Overcome Moral Hazard in Port Concession Agreements. Transportation Research Part E 67: 162-174. 